\title{
LA EVOLUCIÓN DE LA ADOPCIÓN DE TECNOLOGÍA EN LA RED ESTATAL DE EDUCACIÓN DE ESPÍRITO SANTO MEDIDA A PARTIR DE LA GUIA EDUTEC Y LAS PRINCIPALES DEBILIDADES DEL MÉTODO
}

\author{
Érica Rezende Perini \\ ericaperini@gmail.com \\ http://orcid.org/0000-0002-6297-069X \\ Universidade Católica de Petrópolis (UCP) \\ Petrópolis, Brasil. \\ Douglas Bahiense Pereira da Silva \\ douglas@rohling.com.br \\ https://orcid.org/0000-0002-0786-4202 \\ Universidade Católica de Petrópolis (UCP) \\ Petrópolis, Brasil. \\ Carmem Lúcia Prata \\ carmem.prata@gmail.com \\ https://orcid.org/0000-0002-4958-0734 \\ Secretaria de Estado da Educação do Espírito Santo (SEDU) \\ Vitória, Brasil. \\ Valéria Gon Zortéa \\ valeriazortea@gmail.com \\ https://orcid.org/0000-0002-7595-9721 \\ Faculdade Unida de Vitória (FUV) \\ Vitória, Brasil.
}

Recibido: 25/03/2021 Aceptado: 30/09/2021

\begin{abstract}
Resumen
Para ayudar a los gerentes de educación pública a evaluar el nivel de adopción de tecnología en las escuelas y redes estatales de educación, el Centro de Innovación para la Educación Brasileña desarrolló una herramienta de gestión y planificación llamada Guia Edutec para realizar este diagnóstico, defendiendo que el uso de la tecnología en la educación, para apoyar los procesos pedagógicos y procesos de gestión, sólo alcanza su máximo potencial si se tienen en cuenta las siguientes cuatro dimensiones: 1. Visión, 2. Competencias, 3. Contenidos y Recursos Digitales y 4. Infraestructura Tecnológica. A medida que el Departamento de Educación del Estado Brasileño del Espírito Santo aplica anualmente la Guía Edutec en sus escuelas, utilizamos los principios de la investigación cualitativa, a partir de un estudio exploratorio, para investigar la evolución de la adopción de tecnología en esta red estatal de educación, de 2018 a 2019, además de reflexionar sobre las posibles debilidades del método. Encontramos mejoras significativas en las cuatro dimensiones, principalmente en la Infraestructura Tecnológica y menos significativas en la dimensión Visión. Destacamos que, para mejorar la adopción de tecnología en las escuelas, es fundamental la acción innovadora y democrática del Gerente, con el apoyo de una visión estratégica para evaluar los resultados de la Guía Edutec. También se identificaron algunas debilidades en la herramienta. Sin embargo, no comprometen, en su conjunto, los beneficios del método, ya que siempre pueden revisarse y ajustarse.
\end{abstract}

Palabras clave: Adopción de tecnología. Guía Edutec. Cuatro dimensiones. 


\title{
A evolução da adoção em tecnologia na Rede Estadual de Educação do Espírito Santo mensurada a partir do Guia Edutec e as principais fragilidades do método
}

\section{Resumo}

Visando apoiar Gestores da educação pública na aferição do nível de adoção em tecnologia nas escolas e redes de ensino, o Centro de Inovação para a Educação Brasileira desenvolveu a ferramenta de gestão e planejamento Guia Edutec para realizar este diagnóstico, defendendo que o uso da tecnologia na educação, para apoiar processos pedagógicos e de gestão, só atingirá seu pleno potencial se considerar quatro dimensões: 1. Visão, 2. Competências, 3. Conteúdos e Recursos Digitais e 4. Infraestrutura Tecnológica. Assim, visto que a Secretaria de Estado da Educação do Espírito Santo aplica o Guia Edutec anualmente em suas escolas, utilizamos os princípios da pesquisa qualitativa, a partir de um estudo exploratório, para averiguar a evolução na adoção em tecnologia nesta rede de ensino, de 2018 para 2019, além de refletirmos acerca das fragilidades do método. Constatamos melhorias significativas nas quatro dimensões, mais expressivamente na dimensão Infraestrutura e menos considerável na Visão. Ressaltamos que, para melhorar a adoção em tecnologia nas escolas, é primordial a atuação inovadora e democrática do Gestor, com visão estratégica na apreciação dos resultados do Guia Edutec. Algumas fragilidades foram identificadas na ferramenta. No entanto, elas não comprometem, em sua integralidade, seus benefícios, pois permitem revisão e ajustes.

Palavras-chave: Adoção em tecnologia. Guia Edutec. Quatro dimensões.

\section{The evolution of technology adoption in the State Education Network of Espírito Santo measured from the Guia Edutec and the main weaknesses of the method}

\begin{abstract}
To aid public education managers assess the level of technology adoption in schools and education networks, the Innovation Center for Brazilian Education developed a management and planning tool called Guia Edutec to carry out this diagnosis, defending that the use of technology in education, to support pedagogical and management processes, only reaches its full potential if the following four dimensions are taken into account: 1. Vision, 2. Competences, 3. Content and Digital Resources and 4. Technological Infrastructure. From the fact that the State Department of Education in Espírito Santo, Brazil, applies the Edutec Guide annually in its schools, we applied the principles of the qualitative research in an exploratory study to investigate the evolution of technology adoption in the State's education network from 2018 to 2019 and considered about the method's weakness. We found significant improvements in all four dimensions, mainly in the Technological Infrastructure and less significant in the Vision dimension. We emphasize that, in order to improve the adoption of technology in schools, innovative and democratic action by the Manager is essential, with the support of a strategic vision to evaluate the results of the Edutec Guide. A few weaknesses were also identified in the tool. However, they do not compromise, as a whole, the benefits of the method, as they can be always revised and adjusted.
\end{abstract}

Keywords: Technology adoption. Edutec Guide. Four dimensions.

\section{Introdução}

O uso da tecnologia mostra-se cada vez mais inserido no cotidiano das pessoas, seja qual for o contexto considerado: na vida pessoal, social, profissional e educacional. Nessa 
linha, ao discorrerem sobre as percepções de tecnologia no campo educacional, Heinsfeld e Pischetola (2019, p. 5) a inserem como sendo um artefato sociocultural, posto que os desenvolvimentos tecnológicos são entendidos como intrínsecos aos desdobramentos do ser humano e de suas atuações socioculturais. Dessa forma, a tecnologia extrapola os ideais de vilã ou de heroína para traduzir-se em mais uma das manifestações humanas e, conforme altera suas técnicas, é alterada por elas. Assim, "uma tecnologia não pode ser vista como positiva ou negativa, sequer neutra, visto que só pode ser analisada em seus contextos" (HEINSFELD \& PISCHETOLA, 2019, p. 5).

As iniciativas para inserir as Tecnologias de Informação e Comunicação (TIC) na educação básica do Brasil deram seus primeiros passos na década de 1980, quando diversos países direcionaram esforços para definir políticas públicas voltadas para seu uso no contexto educacional (ALMEIDA \& VALENTE, 2016, p. 6). Desde então, a educação é considerada um dos pilares das políticas de inclusão digital, a partir do fomento a investigação, a formação profissional e aos programas de inserção de aparatos tecnológicos, de implantação de infraestrutura nas escolas, de conexão à internet e de preparação de professores (ALMEIDA \& VALENTE, 2016, p. 6).

Cabe pontuar que, no campo educacional, a tecnologia perpassa tanto pelos âmbitos da gestão quanto pelas práticas docentes. Contudo, não é raro nos depararmos com cenários nos quais os sujeitos envolvidos não dispõem de habilidades digitais que permitam explorar suas diversas possibilidades e oportunidades no processo escolar. Por conseguinte, incorporar as tecnologias digitais de informação e comunicação (TDIC), no âmbito educativo, especialmente das redes públicas de ensino, requer estruturações e propostas advindas de políticas governamentais que visam possibilitar à escola responder às demandas de acesso a tais tecnologias. Nesse contexto, ao abordar as ações governamentais que visam à inserção das TDIC nos espaços escolares, depreende-se que essas ações precisam articular duas dimensões: educação e inclusão digital, sob a perspectiva de construção e de reconstrução do conhecimento (FASCIO et al., 2018).

Nessa perspectiva, é preciso compreender que existem diferentes cenários em uma rede estadual e até mesmo em uma escola - tendo em vista seus diferentes turnos de funcionamento. À vista disso, a ideia de soluções homogêneas para todo tipo de contexto torna-se tão falaciosa quanto a noção de que a mera existência das tecnologias digitais no cotidiano escolar permite, automática e autonomamente, potencializar experiências educacionais (HEINSFELD \& PISCHETOLA, 2019, p. 15). A partir dessa defesa, revela-se o desafio posto aos processos educacionais para que as tecnologias não sejam apontadas 
como único fim para garantir a educação com qualidade e equidade. Isto posto, é relevante traçar um histórico de evolução da competência digital nas unidades de ensino para, de fato, avançar e obter o panorama de usos da tecnologia no contexto educativo.

Nessa linha, “os modos de organização e produção da sociedade exigem mudanças na escola que extrapolam os métodos e avançam para transformações em suas concepções, em sua estrutura e em seu funcionamento" (ALMEIDA \& VALENTE, 2016, p. 7) e, considerando as variadas inovações tecnológicas disponíveis para os estudantes do mundo contemporâneo e para as escolas, é primordial delinear o uso das TIC de maneira bem planejada, sobretudo quando se considera a educação pública. Em face disso, o processo de escuta e de pesquisa é uma alternativa exequível para identificar e conhecer as realidades existentes em uma escola ou, ainda, em uma rede de ensino.

Perante o contexto apresentado, a Secretaria de Estado da Educação do Espírito Santo (Sedu/ES) considera o monitoramento da evolução quanto ao domínio de uso das tecnologias nas escolas estaduais uma ação fundamental para o planejamento de políticas públicas nesta área. Além disso, determinados investimentos em infraestrutura, tais como: aquisição de equipamentos, conexão a Internet, instalação de wi-fi e outros que demandam um grande aporte de recursos, precisam estar alinhados com as condições e as necessidades das unidades escolares.

Dessa forma, no ano de 2016, com vistas a alcançar êxito nas demandas que envolvem o uso de tecnologias, a Sedu lançou um Programa - Sedu Digital, executado pela Assessoria Especial de Tecnologia Educacional e voltado para a área da cultura e fluência digital na rede estadual de ensino, que aplica, anualmente, uma ferramenta de gestão nas escolas estaduais, na intenção de mensurar seu nível de adoção em tecnologia ${ }^{1}$. Dessa forma, a partir dos dados levantados, almeja-se não somente a redefinição de prioridades pela Secretaria, mas o planejamento de ações mais efetivas nessa área. Ademais, será possível que cada instituição identifique suas principais lacunas quanto à inserção das TIC nos processos educacionais e de gestão. De posse dessas informações, por meio de devolutivas, as escolas elaboram um plano para definir medidas concretas a serem tomadas para a melhoria dos resultados alcançados.

\section{A parceria entre a Sedu e o Centro de Inovação para a Educação Brasileira}

\footnotetext{
${ }^{1}$ O nível de adoção de tecnologias nas escolas é uma metodologia desenvolvida pelo CIEB para avaliar o nível de Escola Conectada que cada escola se encontra, indicando também caminhos sobre como evoluir.
} 
O Programa Sedu Digital desenvolve ações na área de tecnologia educacional com o objetivo de aprimorar a cultura/experiência digital na rede pública estadual de ensino do ES, o que significa ter diversas frentes de ação integradas ao desenvolvimento e ao fortalecimento do currículo escolar ${ }^{2}$, mantendo-se alinhado ao que preconizam os marcos legais da educação ${ }^{3}$. Assim, desde sua criação, o Programa teve ações presentes em todas as escolas da rede, atuando tanto no desenvolvimento das competências digitais dos professores e equipes gestoras, quanto no fomento ao uso de ferramentas digitais que podem ser aplicadas nas práticas pedagógicas com os alunos.

Mediante tal cenário, no $2^{\circ}$ semestre 2016, o Sedu Digital aplicou o Guia Edutec nas unidades estaduais de ensino - ferramenta de gestão, estruturada pelo Centro de Inovação para a Educação Brasileira $(\mathrm{Cieb})^{4}$, que permite avaliar o quanto a tecnologia está presente nas escolas estaduais, considerando quatro dimensões: Visão, Competência, Conteúdos e Infraestrutura tecnológica. Esta ação resultou no mapeamento do nível de adoção em tecnologia das instituições de educação estaduais. Para mais, os dados levantados apontaram as principais oportunidades e desafios em que o Programa Sedu Digital deveria concentrarse, propiciaram melhor planejamento das ações e do uso da tecnologia nas políticas educacionais do estado em curto, médio e longo prazo e ajudaram a definir as prioridades para o Programa nas dimensões mencionadas.

Em contrapartida, o Cieb oferece apoio técnico às redes públicas de ensino que almejam promover e/ou incorporar inovações educacionais em larga escala, apoiando a criação e o fortalecimento de políticas públicas de tecnologia educacional, de forma a promover maior equidade, qualidade e contemporaneidade na educação pública no Brasil. Por conseguinte, considerando as ações já realizadas com o Sedu Digital, que previa as quatro dimensões citadas desde sua concepção, no ano de 2017, o Cieb manifestou interesse de formalizar uma parceria com a Sedu, sem custos, para apoiar a reestruturação do Programa vigente até então, visando garantir sua sustentabilidade e sucesso. Esta parceria resultou no diagnóstico situacional da tecnologia educacional no estado; a redefinição de ações e prioridades para o Programa a partir da elaboração do Plano Estadual de Inovação e

\footnotetext{
${ }^{2}$ Cita-se: o Plano Escolar de Inovação e Tecnologia, a formação e o assessoramento aos professores e demais profissionais da educação, a criação de ambientes e ferramentas digitais, além da infraestrutura tecnológica necessária nas escolas (por meio da aquisição de equipamentos, de conexão internet e outros relacionados).

${ }^{3}$ Plano Nacional de Educação (PNE); Plano Estadual de Educação do ES; Base Nacional Comum Curricular (BNCC); Política de Inovação Educação Conectada do Ministério da Educação (MEC); Novo Ensino Médio.

${ }^{4}$ O Cieb é uma organização da sociedade civil (OSC) sem fins lucrativos. Em 2016 o Cieb foi convidado pelo Conselho Nacional dos Secretários Estaduais de Educação (Consed) para ser o apoiador técnico de seu grupo de trabalho sobre tecnologia e inovação na educação. Para mais, acesse: https://cieb.net.br/.
} 
Tecnologia; a redefinição de mecanismos de monitoramento de avaliação do Programa e a criação de um modelo de plataforma definido para o Espírito Santo, para que as escolas possam elaborar seus Planos Escolares de Inovação e Tecnologia. Ademais, foram previstos mecanismos para que as escolas tivessem mais autonomia para decidir como seria o uso da tecnologia em seus processos pedagógicos.

\section{O objetivo e o método}

Na visão de Minayo (2016, p. 14), a metodologia de um estudo pode ser entendida como "o caminho do pensamento e a prática exercida na abordagem da realidade" e, para tanto, faz uso de instrumentos e de técnicas para alcançar o conhecimento, todavia "é muito mais que técnicas. Ela inclui as concepções teóricas da abordagem, articulando-se com a teoria, com a realidade empírica e com pensamento sobre a realidade" (MINAYO, 2016, p. 15). E, no presente escrito, utilizamos os princípios dos métodos qualitativos de pesquisa, que "são representados por trabalhos que não necessitam de ferramentas estatísticas" (LEITE, 2008, p. 100), dado que o aprofundamento da compreensão de um grupo social, de uma organização etc. é mais relevante que a representatividade numérica (GERHARDT et $a l ., 2009$, p. 31). Uma característica dos métodos qualitativos está relacionada às situações em que se necessita realizar classificações comparativas, pretendendo identificar proporção, grau ou intensidade de um certo fenômeno e, mesmo existindo uma medida quantitativa, o objetivo exigirá uma classificação (LEITE, 2008, p. 100). Posto isto, “a mudança das coisas não pode ser indefinidamente quantitativa: transformando-se, em determinado momento sofrem mudanças qualitativas. A quantidade transforma-se em qualidade" (LAKATOS, 2003, p. 104).

Para mais, organizamos um estudo exploratório, na intenção de "proporcionar visão geral, de tipo aproximativo, acerca de determinado fato. Esse tipo de pesquisa é realizado especialmente quando o tema escolhido é pouco explorado e torna-se difícil sobre ele formular hipóteses precisas e operacionalizáveis" (GIL, 2008, p. 27). Dessa forma, é um tipo de pesquisa "que explora algo novo e que frequentemente ainda não é considerado ciência, no entanto, serve de base à ciência" (LEITE, 2008, p. 54). Assim, a pesquisa exploratória é de grande valia, uma vez que serve de base a outros tipos de pesquisas, quando a temática possui bibliografia escassa (LEITE, 2008, p. 54).

Selecionamos o método de análise documental, que é um "procedimento que se utiliza de métodos e técnicas para a apreensão, compreensão e análise de documentos dos mais variados tipos" (SÁ-SILVA, ALMEIDA, GUINDANI, 2009, p. 5). De forma 
complementar, ressalta-se que a pesquisa documental também consiste em um intenso e amplo exame de diversos materiais que podem ser reexaminados, buscando-se outras interpretações ou informações complementares (KRIPKA, SCHELLER \& BONOTTO, 2015, p. 58 apud GUBA \& LINCOLN, 1981) e, diante disso, em nosso texto, analisamos documentos institucionais internos e de domínio público da Sedu e do Cieb, no intento de provocar reflexões voltadas para a importância de realizar um diagnóstico das escolas e das redes de ensino com vistas a mensurar o grau de adoção de tecnologia educacional em relação a quatro dimensões.

Em vista disso, o objetivo central deste escrito é analisar como se deu a aplicação da ferramenta de gestão Guia Edutec ${ }^{5}$ na rede estadual de ensino do Espírito Santo e sua evolução na adoção em tecnologia, nos anos de 2018 e 2019, mensurada a partir das quatro dimensões da referida ferramenta, além de refletirmos acerca das fragilidades observadas quanto ao método. Posto isto, destacamos que os dados aqui citados são superficiais do ponto de vista quantitativo, uma vez que optamos por realizar um diagnóstico da metodologia de aplicação da ferramenta utilizada pela Sedu e inferindo sobre os pontos frágeis encontrados.

\section{A ferramenta Guia Edutec e a adoção em tecnologia}

O uso de tecnologias nas práticas pedagógicas e de gestão, quando bem planejado, permite desenvolver aspectos voltados para qualidade, a equidade e a contemporaneidade na educação. No entanto, é primordial a compreensão de que a tecnologia é apenas um meio para promover uma educação significativa. Assim, é importante que não apenas as escolas, mas também a rede de ensino, conheçam seu nível de adoção em tecnologia e possam, a partir daí, efetivar esforços onde é mais necessário.

$\mathrm{Na}$ intenção de apoiar a rede pública de ensino e as escolas na realização desse diagnóstico, o Cieb desenvolveu a ferramenta de gestão e planejamento, denominada Guia Edutec, que foi validada pelo Consed e utilizada pelo MEC, no âmbito do Programa Educação Conectada. A ferramenta considera que o uso da tecnologia na educação para apoiar a gestão na escola e na rede de ensino, o desenvolvimento de competências digitais nos professores e a aprendizagem dos estudantes, só atingirá seu pleno potencial ao considerar quatro dimensões: Visão, Competências, Conteúdos e Recursos Educacionais Digitais e Infraestrutura Tecnológica. Esse instrumento permite mensurar o nível de adoção em tecnologia, em cada dimensão, de cada escola e das redes estaduais de educação.

\footnotetext{
${ }^{5}$ As informações sobre o Guia EduTec constantes neste escrito foram extraídas de documentos oficiais do Cieb e da plataforma da ferramenta.
} 
O Guia Edutec é disponibilizado no formato online e gratuito para todos os estados e todos os municípios do Brasil a partir da plataforma digital oficial da ferramenta ${ }^{6}$ e, de acordo com informações extraídas da referida plataforma, desde sua elaboração, no ano de 2016, o diagnóstico de adoção de tecnologia, realizado a partir do Guia Edutec, em pelo menos um ciclo de aplicação foi realizado em 18.275 escolas, conforme Tabela 1.

Tabela 1 - Total de escolas, por rede de ensino, que realizou o diagnóstico de adoção de tecnologia em pelo menos um ciclo de aplicação, utilizando o Guia Edutec.

\section{Rede de Ensino}

Quantitativo de

Escolas $^{7}$

Escolas da rede pública estadual que realizaram o diagnóstico de adoção de tecnologia.

Escolas da rede pública municipal que realizaram o diagnóstico

de adoção de tecnologia.

Escolas de outras redes (como particular, federal etc.) que realizaram o diagnóstico de adoção de tecnologia.

Total geral de escolas que realizou o diagnóstico de adoção de tecnologia.

Fonte: Tabela elaborada pelos autores a partir de dados disponibilizados na plataforma do Guia Edutec / Cieb em 29/08/2021. Disponível em https://guiaedutec.com.br/painel-geral/escolas.

A orientação é que o Guia Edutec seja respondido pelo Gestor Escolar e por, ao menos, mais dois docentes da escola, sendo um que utiliza a tecnologia em suas práticas com os estudantes e outro que faz pouco uso ou que não utiliza. Nesse processo, o papel do Gestor é bastante significativo, devido ao seu conhecimento acerca das atividades pedagógicas desenvolvidas em todos os turnos da escola e das políticas da Secretaria voltadas para a área de tecnologia educacional. Ademais,

A função de um gestor passa em grande medida pela capacidade de engajar a comunidade escolar em torno de um objetivo maior: melhorar a educação e, no atual contexto, também inseri-la no mundo digital. Como um maestro, cabe a ele extrair o máximo do talento de cada um e fazer com que funcionem como uma orquestra afinada (ALLAN, 2015, p. 161).

Assim, o diagnóstico da escola quanto ao nível de adoção em tecnologia passará pela forma como os Gestores conduzem a ação, dado que será possível definir as prioridades do processo de implementação das tecnologias digitais no contexto escolar. Isso porque a

\footnotetext{
${ }^{6}$ Plataforma do Guia Edutec disponível em: https://guiaedutec.com.br/

${ }^{7}$ Cada escola é contabilizada individualmente, a partir de sua resposta mais recente, mesmo que já tenha realizado o diagnóstico mais de uma vez.
} 
ferramenta consiste em um questionário constituído de 44 questões de múltipla escolha, distribuídas entre as quatro dimensões, sendo que, para cada pergunta, existem 5 cenários possíveis com o qual a escola pode se identificar, contemplando desde escolas completamente equipadas até aquelas desprovidas de infraestrutura tecnológica.

Cada questão possui uma pontuação específica e, partir da alternativa escolhida, a escola pontuará numa escala, sempre por meio de um número inteiro que permite alcançar até 4 pontos, o que possibilitará mensurar a adoção em tecnologia em cada dimensão, segundo a classificação: nível 1 - Emergente; nível 2 - Básico; nível 3 - Intermediário; nível 4 - Avançado. Já em relação à rede de ensino, uma média dos níveis de todas as escolas é calculada. Sendo assim, é possível alcançar um valor decimal, conforme a escala: 1,0 a 1,4 - Emergente; 1,5 a 2,4 - Básico; 2,5 a 3,4 - Intermediário; 3,5 a 4,0 - Avançado.

Imediatamente após responderem o questionário, os Gestores escolares recebem uma devolutiva personalizada, elaborada a partir das respostas fornecidas, em harmonia com o contexto escolar, indicando o nível de adoção da tecnologia em cada uma das dimensões. Após as unidades escolares responderem o formulário, findando o processo, é gerada uma devolutiva personalizada com o resultado da rede de ensino. Nessas devolutivas, estarão elencados os principais desafios e oportunidades encontrados, sugerindo ações prioritárias e medidas concretas que podem ser tomadas, tanto para a rede quanto para a escola. Com essas informações, todos podem entender com mais profundidade as suas prioridades e traçarem seus planos de ação com mais efetividade.

No estado do Espírito Santo, de posse dessa devolutiva, cada Gestor deverá, com a colaboração dos representantes docentes e discentes, analisar atentamente seus resultados alcançados e pensar em estratégias voltadas para aprimorar a maturidade quanto ao uso da tecnologia nas ações da escola, sempre de forma conectada com as políticas do Sedu Digital. Trata-se de um entendimento de que, dentro do princípio democrático, de uma gestão democrática, é fundamental que o colegiado participe das decisões. Esse modelo também garante a corresponsabilização dos envolvidos e maior engajamento de todos na execução das ações.

Para tanto, a Sedu estabeleceu 16 prioridades, sendo 4 para cada dimensão, e caberá ao Diretor Escolar selecionar as 5 que terão maior impacto em sua realidade e nas suas demandas, sendo: 1 prioridade em cada uma das quatro dimensões e 1 prioridade extra na dimensão em que a escola alcançou o pior resultado no Guia Edutec. Dessa forma, será elaborado o Plano Escolar de Inovação e Tecnologia que visa auxiliar na promoção da cultura e da fluência digital, com foco na aprendizagem dos alunos e no desenvolvimento 
profissional dos docentes. Cada prioridade delineada pela Sedu contém várias ações que apontam para o alcance dos resultados almejados. O Sedu Digital também elaborou cadernos orientadores que foram disponibilizados eletronicamente para a rede a partir de um portal, contemplando cada ação prevista do Plano Escolar, integrando os resultados do Guia Edutec com sugestões de tecnologias, de metodologias e de capacitações que possam apoiar as escolas na execução de seu plano.

\section{Compreendendo as quatro dimensões do Guia Edutec}

O Cieb entende que a inovação nos processos educacionais e a utilização das tecnologias enfatiza a inserção da escola no contexto digital e propicia ganhos na gestão, na qualidade, na equidade e na contemporaneidade do ensino. Nessa linha, Almeida e Valente (2016, p. 7) pontuam que "os modos de organização e produção da sociedade exigem mudanças na escola que extrapolam os métodos e avançam para transformações em suas concepções, em sua estrutura e em seu funcionamento". Assim, para mensurar a adoção em tecnologia nas escolas públicas e na rede de ensino, o Guia Edutec foi estruturado considerando quatro dimensões que precisam se manter integradas e em equilíbrio, para que a utilização das TIC seja eficaz, orientada e controlada (ALMEIDA \& VALENTE, 2016, p. $31)$.

As quatro dimensões foram estruturadas com base no conceito de Four in Balance ${ }^{8}$ (Teoria das Quatro Dimensões), cuja base conceitual tem origem na Holanda (ALMEIDA \& VALENTE, 2016, p. 28). Todavia, Almeida e Valente (2016, p. 75) explicam que o conhecimento construído no decorrer da história brasileira sobre o uso das TIC na educação, associado a compreensão da realidade brasileira, um país marcado pela diversidade cultural, educacional e social, levou à ressignificação do modelo original Four in Balance para as políticas nacionais, considerando a relevância da busca de equilíbrio entre as quatro dimensões e ampliando o modelo com a proposta de um novo eixo transversal, composto de currículo, avaliação e pesquisa.

A Teoria das Quatro Dimensões tem sido utilizada tanto no desenvolvimento quanto na avaliação de situações educacionais, visando o uso eficaz e eficiente das TIC na educação (ALMEIDA \& VALENTE, 2016, p. 28). Esse modelo é composto de um elemento humano

\footnotetext{
${ }^{8}$ O Four in Balance (Quatro em Equilíbrio - livremente traduzido como Teoria das Quatro Dimensões) foi desenvolvido em 2001 pela Fundação TIC para a Escola, da Holanda (Stichting Ict op School, 2001), atualmente conhecida como Fundação Kennisnet (Kennisnet, 2016), organização pública de educação e TIC financiada pelo Ministério da Educação, Cultura e Ciência.
} 
e um tecnológico, sendo que o elemento humano é constituído pelos eixos visão e competência; e o elemento tecnológico contempla os eixos recursos educacionais digitais e infraestrutura (ALMEIDA \& VALENTE, 2016, p. 28), ou seja, não adianta priorizar os investimentos em uma das dimensões e desfavorecer a outra, visto que todas são relevantes, conforme detalhamento a seguir.

- Visão: refere-se ao quanto se acredita que a tecnologia tem o potencial de impactar positivamente as escolas, promovendo um ensino de qualidade e uma gestão escolar eficaz. Ou seja, trata da integração da tecnologia no planejamento pedagógico a partir do mapeamento da adoção em tecnologia das escolas. Contempla, também, as maneiras em que tal crença se reflete em estratégias e políticas planejadas para que as escolas atinjam seus objetivos.

- Competências/Formação: indica as habilidades e competências que a equipe escolar precisa ter para o uso potencializado de tecnologias na educação. Contempla as habilidades dos professores (conhecimento e atitudes em relação ao uso de TIC e as formas de uso das ferramentas de TIC na prática pedagógica) e da equipe gestora (sua habilidade quanto ao uso de TIC para melhorar a gestão escolar e apoiar docentes e discentes a utilizarem melhor as ferramentas). Logo, para garantir essas habilidades e competências, é preciso dispor de formações para o uso de tecnologia para os profissionais da educação.

- Conteúdos e Recursos Digitais: diz respeito à curadoria, acesso e uso de programas, aplicativos, objetos e conteúdos digitais utilizados na instituição escolar, visando facilitar o processo educativo e a gestão educacional. Assim, é preciso estruturar ambientes e ferramentas digitais de conteúdos e de comunicação, incorporadas ao currículo escolar, para o desenvolvimento da aprendizagem.

- Infraestrutura: trata da disponibilidade e da qualidade de computadores e demais equipamentos da escola, além do acesso e qualidade da conexão com a Internet. Inclui também a gestão e disponibilidade desses recursos.

Diante do exposto, para pensar no uso efetivo da tecnologia da educação, é primordial entender a relevância da intencionalidade pedagógica nas ações executadas e a necessidade de mudar conceitos e comportamentos, direcionando o olhar para além dos recursos tecnológicos (infraestrutura), que são apenas um meio para alcançar bons resultados. Em outras falas, a compreensão dessas quatro dimensões, considerando sua real importância para o processo pedagógico apoiado no uso das TIC, auxilia no alcance da maturidade da equipe escolar quanto ao nível de apropriação e de conhecimentos para a utilização dos recursos 
tecnológicos disponíveis, refletindo em um alto nível de adoção em tecnologia nas escolas públicas. Em vista disso, o Guia Edutec viabiliza a possibilidade de conhecer como está a adoção em tecnologia, em cada uma das quatro dimensões, de cada unidade escolar e também da rede estadual de ensino.

\section{A evolução do nível de adoção em tecnologia na rede estadual de educação do Espírito Santo de 2018 para 2019}

Para que os resultados do Guia Edutec sejam considerados censitários pelo Cieb, é necessário que, no mínimo, $80 \%$ das escolas da rede respondam ao questionário. No que se refere aos dados do Espírito Santo, a primeira aplicação da ferramenta no estado aconteceu no ano de 2016, coordenado pelo Programa Sedu Digital com apoio do Cieb. O questionário online permaneceu aberto para receber respostas por um período pré-fixado de 60 dias, sendo prorrogado por mais 30 dias, e foi respondido por $99,58 \%$ das 480 unidades de ensino ativas que compunham a rede estadual de ensino (equivalente a 478 escolas respondentes). No ano de 2017, a Sedu não aplicou o questionário, uma vez que a execução de 2016 aconteceu no final do ano e as escolas elaboraram e implementaram seus Planos Escolares de Inovação e Tecnologia durante o ano de 2017.

Em 2018, o Guia Edutec foi reformulado e novamente aplicado em todas as escolas estaduais com mais de 20 estudantes matriculados, o que correspondeu a 404 escolas cadastradas, com um total de 397 (98,3\%) respondentes. Já em 2019, o Guia foi aplicado nas instituições de ensino com mais de 60 estudantes, englobando 402 escolas e com 399 respondentes (99,3\%). Os resultados alcançados, ano a ano, para a rede estadual do Espírito Santo são de grande relevância, pois auxiliam na tomada de decisões, de maneira a delinear o planejamento das ações da Assessoria Especial de Tecnologia Educacional (Sedu Digital) para o ano seguinte.

No ano de 2020, não houve aplicação do Guia Edutec na rede estadual de educação do Espírito Santo, tendo em vista o cenário desencadeado pela Covid-19, doença causada pelo novo coronavírus que começou a atingir o mundo em 2019 e levou a Organização Mundial de Saúde (OMS) a declarar o surto como uma pandemia que alcançou o Brasil em março do ano em questão e, por conseguinte, impactou diretamente escolas com a interrupção total das aulas presenciais. Assim, as ações e prioridades estabelecidas pela Sedu foram reorganizadas no intento de minimizar os impactos na educação pública estadual. Isto posto, para este artigo, consideramos apenas os dados relativos aos anos de 2018 e 2019 , tendo em vista a uniformidade dos elementos coletados nestes dois anos. Nesse sentido, o 
nível de adoção de tecnologia da rede estadual de ensino do Espírito Santo, em cada uma das quatro dimensões do Guia Edutec, obtidos nos anos de 2018 e 2019, e calculadas partir das escolas respondentes, constam nas Tabelas 2 e 3 a seguir.

Tabela 2 - Nível de adoção de tecnologia da rede estadual de educação do Espírito Santo, por dimensão, calculado a partir dos resultados do Guia EduTec $(2018,2019)$

\begin{tabular}{ccccc}
\hline Ano & Visão & Competências & $\begin{array}{c}\text { Conteúdos e } \\
\text { REDig }\end{array}$ & Infraestrutura \\
\hline $\mathbf{2 0 1 8}$ & 2,3 & 2,4 & 2,9 & 2,5 \\
$\mathbf{2 0 1 9}$ & 2,5 & 2,8 & 3,1 & 3,0 \\
\hline
\end{tabular}

Fonte: Tabela elaborada pelos autores a partir de dados extraídos de relatórios enviados pelo Cieb para a Assessoria Especial de Tecnologia Educacional (Sedu, 2020).

Os resultados apresentados nas Tabelas 2 mostram que houve uma melhoria significativa nas notas alcançadas em todas as dimensões em ambos os anos, sinalizando a melhoria da adoção em tecnologias pelas escolas. A dimensão Infraestrutura foi a que teve a evolução mais expressiva ( 0,5 pontos), o que era esperado pela Secretaria, tendo em vista os diversos investimentos realizados, como a aquisição de Chromebooks para 194 unidades de ensino da rede e instalação de wi-fi nas escolas, inclusive nas salas de aula. Em contrapartida, a dimensão Visão foi a menos desenvolvida nos dois anos considerados, o que sugere que a compreensão dos Diretores acerca da importância da tecnologia nos processos pedagógicos e de gestão na atualidade precisa ser aprimorada e, por tal motivo, demanda ações prioritárias por parte da Sedu. Ademais, tal dimensão "engloba os objetivos básicos da instituição e aborda as condições necessárias para atingir seus objetivos, as crenças sobre os papéis do professor e dos alunos, a escolha de metas e materiais e a atuação dos gestores" (ALMEIDA \& VALENTE, 2016, p. 29), que precisam ter uma postura comprometida e engajada.

Percebemos ainda a tendência de um equilíbrio entre as quatro dimensões, o que pode ser compreendido como algo bastante relevante, pois permite que a Sedu estabeleça ações para que a rede de ensino evolua entre as dimensões de forma equiparável. De forma complementar, avaliando isoladamente cada dimensão, extraímos o percentual de escolas em cada nível de adoção em tecnologia (emergente, básico, intermediário e avançado) e organizamos na Tabela 3.

Tabela 3 - Percentual de escolas estaduais do Espírito Santo em cada nível de adoção em tecnologia, em cada dimensão $(2018,2019)$ 


\begin{tabular}{ccccccccc}
\hline \multirow{2}{*}{ Dimensão } & \multicolumn{2}{c}{ Emergente } & \multicolumn{2}{c}{ Básico } & \multicolumn{2}{c}{ Intermediário } & \multicolumn{2}{c}{ Avançado } \\
& $\mathbf{2 0 1 8}$ & $\mathbf{2 0 1 9}$ & $\mathbf{2 0 1 8}$ & $\mathbf{2 0 1 9}$ & $\mathbf{2 0 1 8}$ & $\mathbf{2 0 1 9}$ & $\mathbf{2 0 1 8}$ & $\mathbf{2 0 1 9}$ \\
\hline Visão & $10 \%$ & $4 \%$ & $52 \%$ & $48 \%$ & $32 \%$ & $41 \%$ & $4 \%$ & $5 \%$ \\
$\begin{array}{c}\text { Competências } \\
\text { Conteúdos e } \\
\text { REDig }\end{array}$ & $12 \%$ & $5 \%$ & $36 \%$ & $31 \%$ & $42 \%$ & $47 \%$ & $8 \%$ & $16 \%$ \\
\begin{tabular}{c} 
Infraestrutura \\
\hline
\end{tabular} & $3 \%$ & $0 \%$ & $18 \%$ & $11 \%$ & $67 \%$ & $65 \%$ & $13 \%$ & $23 \%$ \\
\hline
\end{tabular}

Fonte: Tabela elaborada pelos autores a partir de dados extraídos de relatórios enviados pelo Cieb para a Assessoria Especial de Tecnologia Educacional (Sedu, 2020).

As informações indicadas da Tabela 3 confirmam a melhoria dos resultados nos anos de 2018 para 2019, com relevantes quedas nos percentuais de escolas que estavam classificadas nos níveis emergente e básico, em todas as quatro dimensões, refletindo o aumento de escolas classificadas nos níveis intermediário e avançado. Assim como no resultado geral da rede estadual, novamente percebemos o considerável crescimento do quantitativo de escolas que evoluíram para o nível avançado na dimensão Infraestrutura, assim como o crescimento pouco expressivo para a dimensão Visão.

Com fins de informação complementar, cabe registrarmos que, em um estudo realizado no ano de 2018 por Fascio et al. acerca da aplicação do Guia Edutec para identificar o nível de adoção de tecnologia em escolas do núcleo regional de educação de Maringá (PR), os autores constataram que as escolas apresentaram distinção tanto nos níveis de apropriação tecnológica quanto nas quatro dimensões, denotando que investimentos e medidas que não considerarem tais diferenças tendem a obter pouco ou nenhum retorno. Os autores ainda pontuaram que a aplicação da ferramenta, seguida da devolutiva, permite tanto ao estado quanto às escolas implementarem ações individualizadas e, portanto, adequadas à dimensão e ao nível em que cada instituição de ensino se encontra. (FASCIO et al., 2018). Assim, com o findar das explicações que envolvem a aplicação do Guia Edutec nas escolas estaduais do Espírito Santo, além da apreciação dos resultados que demonstram a evolução na adoção em tecnologia pelas escolas e pela rede de ensino, na intenção atender ao objetivo deste artigo, dissertaremos sobre as fragilidades observadas quanto ao método empregado para mensurar a maturidade na adoção em tecnologia das escolas e da rede estadual de ensino.

\section{As fragilidades observadas no método utilizado para o diagnóstico}

A orientação do Cieb, acolhida pela Sedu, é que o Guia Edutec fosse respondido pelo Gestor Escolar, tendo em vista seu conhecimento da realidade de todos os turnos da escola, 
e por, ao menos, mais dois professores da escola, sendo um que faça uso da tecnologia com alunos e outro que não a utilize ou utilize pouco. No entanto, a ferramenta realiza o registro os dados daqueles que logam na plataforma para responderem o questionário e, perante a apreciação destes dados a parir de documentos internos da Secretaria ${ }^{9}$, constatamos que nem sempre os respondentes foram aqueles que atendiam ao perfil sugerido pelo Cieb, como orientado pelo Sedu Digital, sugerindo que alguns Diretores delegaram a ação a outras pessoas de sua equipe.

Contudo, ressaltamos ser de nosso conhecimento que as condições das unidades escolares são diversas e, por tal motivo, não é possível garantir que em todas as instituições haja a situação ideal. Em relação à participação ou a não participação dos Diretores, é possível que, nos períodos de aplicação do Guia do Edutec, alguns estivessem em gozo de férias, em licença ou fossem recém-chegados, iniciando seu exercício na escola e com pouco conhecimento a respeito do cotidiano pedagógico de todos os turnos. É possível, ainda, que a escola estivesse no período de processo seletivo para escolha do Diretor. O Pedagogo/Coordenador Pedagógico também poderia ser novo na escola, com pouco conhecimento do todo. Mediante tais contextos, corre-se o risco de que respondentes nessas situações explicitem uma visão pessoal ou apenas de seu turno de trabalho e não do conjunto das ações da escola, em todos os horários de funcionamento. Seria interessante, então, que a logística de aplicação do Guia Edutec incluísse orientações prévias, para que o tempo de atuação dos respondentes na instituição seja suficiente para fornecer respostas que reproduzam a realidade mais próxima possível da escola como um todo.

Por conseguinte, entendemos ser relevante averiguar, no que tange à maneira como a escola usa a tecnologia disponível, se os dados informados correspondem de fato ao cenário real da escola, em todos os turnos, tendo em vista que a realidade de uma escola de tempo parcial é distinta em cada turno de funcionamento, com vivências específicas do público (docentes e discentes) daquele período. O mesmo não acontece nas escolas de tempo integral, em que os professores permanecem todo o período de estudos com os mesmos alunos e seu funcionamento não se dá por turnos.

Assim, nas escolas de tempo parcial, que compõem a maioria das unidades de ensino da rede, a participação na aplicação do Guia Edutec de, pelo menos, um professor da instituição escolar por turno, acompanhado de Pedagogos/Coordenador Pedagógico, talvez

\footnotetext{
${ }^{9}$ Considerando a necessidade de manter a ética na pesquisa, os dados quantitativos e qualitativos relativos às escolas cujos respondentes não foram aqueles orientados pelo Sedu Digital não serão divulgados, uma vez que fazem parte de documentos internos da Secretaria e não temos autorização formal para divulgar.
} 
fosse mais adequada para construção do retrato da escola, uma vez que os itens abordados no questionário buscam descrever o cotidiano educacional e o envolvimento dos docentes no que se refere ao uso das ferramentas digitais em cenários diversos do processo educativo. Dessa maneira, é possível que nem sempre a informação coletada represente exatamente a realidade da escola em todas as quatro dimensões. Para mais, vale lembrar que para cada pergunta de múltipla escolha do questionário, existem cinco cenários possíveis, que perpassam desde ao não uso da tecnologia à elevada maturidade para o uso da tecnologia (a tecnologia inserida no cotidiano escolar). Isto posto, os dados podem refletir também a ótica dos respondentes e não a dos turnos totais da escola.

Outro ponto de atenção deve-se ao fato de que o formulário demanda em torno de 30 minutos apenas para resposta e, em cada ano de aplicação, foi previsto o período de 60 dias para que todas as escolas finalizassem a ação. Portanto, visando à participação efetiva dos Diretores, a Sedu os mobilizou, por meio de e-mails, de publicações em redes sociais e do envio de mensagens em grupos de trabalho. Entretanto, tais estratégias parecem não terem sido suficientes para alcançar o envolvimento de $100 \%$ dos Gestores das escolas no tempo previsto, uma vez que foi necessário prorrogar o período de aplicação para mais 30 dias. Diante disso, é preciso que a Secretaria analise quão eficiente ou não foi a ação de comunicação para alcançar o objetivo da ação de realizar o diagnóstico da apropriação tecnológica das escolas estaduais do ES e da rede estadual de ensino.

À vista disso, a dimensão Visão se mostrou a menos desenvolvida nas duas aplicações analisadas. Essa dimensão também trata da compreensão, por parte dos Gestores, do quanto a tecnologia é importante e do quanto sua ausência pode impactar nos processos educativos da atualidade, basta observar sua aplicação nos processos de matrícula online, no diário de classe online, nos processos de formação EAD, na comunicação em tempo real, assim como ter ciência da importância da coleta de dados para definir políticas. É necessária, então, a compreensão da equipe escolar, sobretudo da equipe gestora, que pesquisas de levantamento de dados requerem respostas corretas e informadas no tempo estipulado, uma vez que são fundamentais para que as áreas responsáveis pela elaboração de políticas façam seu planejamento a tempo de atender as escolas ao longo do calendário letivo.

Outra situação observada está relacionada à elaboração, por parte das escolas, do Plano Escolar de Inovação e Tecnologia, após receberem a devolutiva do Guia Edutec, que consiste na seleção de ações vinculadas a cada dimensão que contemplam um determinado nível de adoção quanto ao uso da tecnologia. Segundo consta no Site Plano Escolar de Inovação e Tecnologia, a orientação da Sedu é que os Diretores apresentem a Devolutiva do 
Guia Edutec para a equipe pedagógica, assim como para os representantes discentes, de forma a definirem coletivamente as ações mais adequadas para a realidade escolar. Essa estratégia é inovadora e fomenta o uso dos resultados do Guia Edutec. No entanto, não há como comprovar se os Diretores compartilharam a devolutiva com sua equipe, se a equipe selecionou as ações do Plano Escolar conjuntamente - ou se foi feita apenas pela equipe gestora - ou ainda se o Diretor participou da seleção das ações em parceria com sua equipe, caso tenha havido esse movimento.

De forma complementar, também pontuamos acerca da não participação dos alunos no processo de aplicação do Guia Edutec nas escolas, dado o fato de existir a orientação de participação dos representantes discentes na etapa de apresentação e discussão da devolutiva do Guia, tendo em vista que são eles os principais interessados/contemplados na inovação dos processos educativos. Isso poderia favorecer a corresponsabilização e o engajamento dos jovens no processo educacional, no uso inovador das ferramentas digitais e no cuidado para com os equipamentos disponíveis na escola.

Destacamos também que, infelizmente, não há dados acerca do acesso aos cadernos orientadores produzidos e disponibilizados pelo Sedu Digital para a elaboração do Plano Escolar de Inovação e Tecnologia de maneira integrada aos resultados do Guia Edutec, tampouco da execução dos Planos pelas escolas. Com a chegada da pandemia ao Brasil, essas ações foram suspensas para atender outras demandas da Secretaria. Por fim, é importante pontuarmos que esse conjunto de fragilidades observadas quanto ao método utilizado para realizar o diagnóstico de adoção em tecnologia nas escolas e redes de ensino é frequentemente observado e estudado, especialmente pela Secretaria e pelo Cieb, na intenção de buscar estratégias que possibilitem sanar as vulnerabilidades que possam comprometer a veracidade das informações. Por esse ângulo, a técnica alinha-se ao defendido por Almeida e Valente (2016, p. 74) ao afirmarem que as políticas precisam ser revistas em sua elaboração, implantação, implementação e avaliação, sendo importante olhar o passado e destacar as lições aprendidas, de modo a projetar o futuro a partir do que foi possível realizar no presente.

\section{Considerações finais}

Neste estudo, buscamos compreender os caminhos trilhados para aplicação da ferramenta de gestão Guia Edutec na rede estadual de ensino do Espírito Santo e apreciarmos a evolução da adoção em tecnologia desta rede nos anos de 2018 e 2019. Em contrapartida, também pontuamos acerca das fragilidades observadas quanto ao método utilizado para a 
realização do diagnóstico, que está pautado na Teoria das Quatro Dimensões (Four In Balance).

Em relação aos resultados alcançados pela rede estadual de educação do Espírito Santo, observamos uma melhoria nos resultados de 2018 para 2019 em todas as quatro dimensões, manifestando-se de forma mais expressiva na dimensão Infraestrutura e menos expressiva na dimensão Visão. O resultado relativo à Infraestrutura era previsto pela Sedu, uma vez que foram realizados vários investimentos destinados à aquisição de equipamentos e a instalação de wi-fi nos diversos espaços escolares, inclusive nas salas de aula. Por outro lado, a evolução pouco expressiva da dimensão Visão sugere que os Diretores Escolares carecem de mais apropriação acerca da relevância de considerar a tecnologia no contexto escolar, de maneira estratégica e inovadora, visando o aperfeiçoamento dos processos pedagógicos e de gestão.

Entendemos que, para melhorar o nível de adoção em tecnologia nas escolas na rede de ensino, é preciso atuar numa perspectiva inovadora e democrática, o que demandará um Gestor com visão estratégica, no que concerne à apreciação dos resultados do Guia Edutec, seja no âmbito de uma unidade escolar ou no âmbito da rede estadual de ensino, sobretudo no que tange a dimensão Visão que, para o estado do Espírito Santo, é a menos desenvolvida na rede e nas escolas. Esta ação perpassa pela maneira como os órgãos comunicam suas políticas e em como a "ponta" recebe e codifica a informação, dando prioridade ou não a ela, e considerando que a comunicação de uma política é tão fundamental quanto a política em si. Saber comunicar uma ideia de maneira efetiva, atrelando-a a importância do engajamento do setor responsável, é primordial para que todos compreendam o seu papel na ação.

Em suma, ao encerrar as reflexões aqui apresentadas, constatamos que as fragilidades apontadas quanto ao método utilizado para a aferição da apropriação tecnológica nas escolas e na rede de ensino não comprometem, em sua integralidade, os benefícios da ferramenta, visto que permitem revisão e ajustes. Assim, é preciso considerar todo o processo envolvido, especialmente as informações na Devolutiva sobre os resultados alcançados, que precisam ser publicizados com a comunidade escolar, além da posterior elaboração do Plano Escolar de Inovação e Tecnologia, que deve ser feita colaborativamente com a equipe docente e os representantes discentes. Nessa perspectiva, entendemos que a ferramenta Guia Edutec cumpre seu papel, no tocante a aferição da apropriação tecnológica, se executada conforme orientações do Cieb e da Secretaria. 


\section{Referências}

ALLAN, L. Escola.com: como as novas tecnologias estão transformando a educação na prática. Barueri, SP: Figurati, 2015.

ALMEIDA, M. E. B. de; VALENTE, J. A. Políticas de Tecnologia na Educação Brasileira - histórico, lições aprendidas e recomendações. CIEB ESTUDOS \#4. 2016. Disponível em: https://cieb.net.br/downloads/. Acesso em: 30 dez.2020.

ESPÍRITO SANTO. Boletim de resultado Guia Edutec 2016, com orientações. Disponível em: https://drive.google.com/file/d/0B3GITFf97UH_N2R4RGpCNkxPRVk/view. Acesso em: 28 dez.2020.

ESPÍRITO SANTO. Guia Edutec - Relatório de Resultados do Guia Edutec 2018. Disponível em: https://drive.google.com/file/d/1t72pQr73pOyx2aMeI7JxDJAIIGGcjS76/view. Acesso em: 06 jan. 2021.

ESPÍRITO SANTO. Guia Edutec - Relatório de Resultados do Guia Edutec 2019. Disponível em: https://drive.google.com/file/d/1gQBlqYri0Bj45eOvk0gadKJMzGoXIDQ2/view. Acesso em: 06 jan. 2021.

ESPÍRITO SANTO. Relatório Programa Sedu Digital 2017. Disponível em: https://drive.google.com/file/d/1gT9KUZHy8A9g4QyOnM0VV1lDcK8kbBB3/vie W. Acesso em: 28 dez. 2020.

ESPÍRITO SANTO. Relatório Programa Sedu Digital 2018. Disponível em: https://drive.google.com/file/d/1aXB2Xzep2ZR2P9RBgxmWaoIW7HWlEPrF/vie W. Acesso em: 28 dez. 2020.

ESPÍRITO SANTO. Relatório Programa Sedu Digital 2019. Disponível em: https://drive.google.com/file/d/1YHKZZ_snq9cjx27WT6q-YIwVx4HW3Tp7/view. Acesso em: 28 dez. 2020.

FASCIO, O. A. S.; ALMEIDA, I. C. de; FORNO, L. F. D. Ferramenta Four In Balance: identificando o nível de adoção de tecnologia em escolas do núcleo regional de educação de Maringá. Anais do V CONEDU - Congresso Nacional de Educação. Campina Grande: Realize Editora, 2018. Disponível em: https://editorarealize.com.br/artigo/visualizar/47425. Acesso em: 10 jan. 2021.

GERHARDT, T. E. et al. In: GERHARDT, T. E.; SILVEIRA, D. T. Métodos de pesquisa. Porto Alegre; RS: Editora da UFRGS, 2009.

GIL, A. C. Métodos e técnicas de pesquisa social. $6^{\text {a }}$ ed. São Paulo, SP : Atlas, 2008.

HEINSFELD, B. D.; PISCHETOLA, M. O discurso sobre tecnologias nas políticas públicas em educação. Educação e Pesquisa. Revista da Faculdade de Educação da USP. vol.45, São Paulo, 2019. Disponível em: http://www.scielo.br/pdf/ep/v45/15179702-ep-45-e205167.pdf. Acesso em: 08 fev. 2021.

KRIPKA, R. M. L.; SCHELLER, M.; BONOTTO, D. L. Pesquisa documental na pesquisa qualitativa: conceitos e caracterização. Revista de investigaciones UNAD. vol. 14, $\mathrm{n}^{\mathrm{o}} 2$, julio-diciembre, 2015, p. 55-73. Bogotá. Colombia.

LAKATOS, E. M. Fundamentos de metodologia científica. 5 ed. - São Paulo : Atlas, 2003. 
LEITE, F. T. Metodologia Científica: métodos e técnicas de pesquisa: monografias, dissertações, teses e livros. Aparecida-SP : Ideias \& Letras, 2008.

MINAYO, M. C. de S (Org.); DESLANDES, S. F.; GOMES, R. Pesquisa Social: Teoria, método e criatividade. Petrópolis, RJ : Vozes, 2016 (Série Manuais Acadêmicos).

PLATAFORMA Guia Edutec. Disponível em: https://guiaedutec.com.br/. Acesso em: 15 dez. 2020.

PORTAL Centro de Inovação para a Educação Brasileira (CIEB) - Guia EduTec. Disponível em: http://www.cieb.net.br/guia-edutec/. Acesso em: 17 dez. 2020.

PORTAL Plano Escolar de Inovação e Tecnologia. Disponível em: https://sites.google.com/edu.es.gov.br/planoinovacao/. Acesso em: 10 jan. 2021.

PORTAL Sedu Digital. Disponível em: http://sedudigital.edu.es.gov.br/. Acesso em: 20 dez. 2020.

SÁ-SILVA, J. R.; ALMEIDA, C. D. de; GUINDANI, J. Fe. Pesquisa documental: pistas teóricas e metodológicas. Revista Brasileira de História \& Ciências Sociais. (2009). 1(1). p. 1-15.

Autores

Érica Rezende Perini

Secretaria de Estado da Educação do Espírito Santo

Doutoranda em Educação

Programa de Pós-graduação em Educação da Universidade Católica de Petrópolis

(PPGE/UCP)-Tecnologias na Educação ericaperini@gmail.com

Douglas Bahiense Pereira da Silva

Universidade Católica de Petrópolis

Especialista em Filosofia Moderna e Contemporânea

Programa de Pós-graduação em Educação da Universidade Católica de Petrópolis

(PPGE/UCP)-Educação

douglas@rohling.com.br

Carmem Lúcia Prata

Secretaria de Estado da Educação

Mestrado em educação

Tecnologias na educação

carmem.prata@gmail.com

Valéria Gon Zortéa

Secretaria de Estado da Educação do Espírito Santo

Mestra em Ciências das Religiões

Programa de Pós Graduação em Ciências das Religiões da Faculdade Unida de Vitória/ES

Ensino Religioso Escolar valeriazortea@gmail.com 